\title{
Editorial
}

\section{A New Editor on the Occasion of the Centennial Celebration of the Journal (Maybe)}

In 1983, I was delighted to publish my first paper in The American Journal of Pathology and I remember equally well preparing an overview for the Journal in 1990, concurrent with receiving the Warner-Lambert/Parke-Davis (now Pfizer) Award of the American Society of Investigative Pathology. I felt honored both times, recognizing the strength and reputation of the Journal in our field. Subsequently, given Nelson Fausto's almost 10 years of stewardship as Editor-in-Chief, the Journal has only gained in stature, now having by far the highest impact in the field. Last July, the Journal began a transition, completed January 1,2001 , to a recast group of Editors. Our task of guiding the Journal over the next few years also happens in a remarkable year-what had been thought for years to be the 100th anniversary of this publication. Accordingly, I will say a few words concerning a centennial anniversary surprise and, subsequently, a few more words about our new group of editors.

The Birth Date of the Journal and Its Link to The Journal of The Boston Society of Medical Sciences

Until recent investigative work done by the Editorial Office (largely by the ever-astute Managing Editor, Priscilla Markwood), as groundwork for this piece, it was anticipated that 2001 would unquestionably be the centennial anniversary of The American Journal of Pathology. It had been assumed that the Journal's inaugural issue was in 1901 when it first appeared as The Journal of Medical Research published by the Harvard University Press. In 1925 the title was changed to the current title, The American Journal of Pathology. The first Editor-in-Chief under this new title was the well-known Frank Burr (F.B.) Mallory. To our surprise, in researching the background for this piece we learned that, by any legitimate reckoning, we likely missed the anniversary date by some five years! Indeed, a journal entitled The Journal of the Boston Society of Medical Sciences, was first published in 1896 and it was this journal which appears to have evolved into The Journal of Medical Research and subsequently into Mallory's The American Journal of Pathology.

On September 9, 1869 a group of academic physicians in Boston (largely made up of faculty of Harvard
Medical School) founded the Boston Society of Medical Sciences to promote the sciences as they are connected with medicine. Prominent in the administrative organization of this new Society was Dr. Harold Ernst, a bacteriologist who studied diphtheria, staphylococci, and plague. A review of the minutes from 1887 to 1914 of this organization (conducted by Jack Eckert of Harvard Medical School's Countway Library where these papers are stored) found the following resolution of the Executive Committee of the Boston Society of Medical Sciences dated December 19, 1895: "Voted that, to further the best interests of the (Harvard Medical) School, the Faculty requests each head of department to have at least a summary of the scientific investigations made in his department presented at a meeting of the Boston Society for Medical Sciences for preservation in its Journal." Other than the assumption that a department head is necessarily of male gender, this quote is notable in additional ways. As you will see, the date of this resolution-December 19, 1895 with the first issue printed in 1896-might well be considered the official birthdate of The American Journal of Pathology. In its second year, 1897, the October issue of the Journal proclaims that it "will contain full abstracts of experimental work carried on in the following institutions: the Medical School of Harvard University, the Experimental Laboratories of the Massachusetts General and the Boston City Hospitals, the Physiological and Biological Departments of the Massachusetts Institute of Technology, and Clark University. Papers and abstracts of papers on subjects connected with the Medical Sciences will be welcomed from persons not members of the Society, and if approved by the Council, will be presented at the meetings, and abstracts will be given a place in the Journal." The Journal of the Boston Society of Medical Sciences was thus rich in abstracts, although unlike our current view of abstracts, these often took the

We gratefully acknowledge the assistance of the following individuals and institutions in research associated with this article: Jack Eckert, Reference Librarian, Rare Books and Special Collections, Francis A. Countway Library of Medicine, Harvard Medical School; Virginia A. Hunt, Curatorial Assistant for Museum and Archives Collections, Warren Anatomical Museum/Rare Books and Special Collections, Harvard Medical School; Debra Slingluff, Milton Eisenhower Library, Johns Hopkins University; and Regina Reynolds, Head, National Serials Data Program, U.S. Library of Congress. 
form of an abbreviated paper. The Society published the Journal and the financial implications of this arrangement were debated from time to time as recorded in the Society's minutes.

Examples of the titles from manuscripts/abstracts appearing in The Journal of the Boston Society of Medical Sciences (reflective of the efforts in the various Departments of Harvard Medical School, see above) as published in issues around the turn of the century are interesting to note: "Fifty Normal Blood Counts," "Public Baths in Europe," "General After-Effects of Ether," "An Improved Microtome," "The Weight of Normal Hearts in Adults," and "Coordination of Heart Muscle without Nerve Cells." Authors were the likes of H.P. Bowditch, W.T. Councilman, and F.B. Mallory.

\section{The Journal of Medical Research}

At the Society Council meeting of April 1, 1901, the first mention was made of possibly enlarging the scope of this highly successful endeavor in conjunction with formation of the American Association of Anatomists and Pathologists. Possible journal name changes were discussed at the following meeting and, at the June 21 meeting, there was a unanimous vote "to establish a new scientific journal, as a continuation of The Journal of the Boston Society of Medical Sciences, under the title The Journal of Medical Research." Harold Ernst was named Editor-in-Chief. Dr. Ernst, of course, was not a pathologist and it is both interesting and ironic that, at the meeting just prior to the June 21 meeting the Council had unanimously favored another name. That unused name? The Journal of Pathology!

From 1901 to 1925, the Journal existed as The Journal of Medical Research. The content blended issues from the fields of laboratory medicine and anatomical pathology, most often with an eye toward experimentation with material derived from humans or from animal models relevant to human disease. Representative titles from this period include: "The Estimation of Leukocytes from Stained Blood Smears," "Agglutinins and Precipitins in Anti-Gonococcic Serum," "The Application of the CardCabinet System in the Storage of Microscopical Slides Preparations," "A Colorimetric Test for Cholesterol," "Some Observations on the Cultivation of Tissues in Culture," and "Tests of the Efficiency of Pasteurization of Milk under Practical Conditions." Since authorship was no longer restricted to members of the Boston Society of Medical Sciences, the Journal quickly took on a more national flavor.

\section{The American Journal of Pathology}

The Journal finally came to its current name with the first issue in January of 1925, with, as mentioned above, F.B. Mallory as Editor-in-Chief. The first entry was by the famed Ernest Goodpasture (The American Journal of Pathology 1925, 1:1-11) and was entitled "Intranuclear Inclusions in Experimental Herpetic Lesions of Rabbits." The first issue alone had papers not only by Goodpasture, but also by Wilder Penfield, Louise Meeker, and F.B.
Mallory. In the second issue (in March of 1925 as the Journal was, at first, published only on a quarterly basis), Shields Warren, the late famous radiation biologist and experimental pathologist (who, I recall, castigated me when, in 1975, as a new pathology resident at the New England Deaconess, I asked him why the Harvard Departments historically didn't interact more), wrote on "The Etiology of Acute Appendicitis" and Francis Peabody presented evidence of phagocytosis of erythrocytes in pernicious anemia. Later that year, Fred Stewart presented his observations on focal tuberculin hypersensitivity in an infected organ previously sensitized, and William Boyd described the diffuse tumors of the meninges.

Within the first five years of the Journal under this current title, other authors included Harvey Cushing, S. Burt Wolbach, Soma Weiss, and Pierre Masson. Goodpasture was particularly prolific, producing a series of papers on human and animal models of encephalitis and on immune responses to fowl pox. Soon many papers appeared characterizing classical immunological responses. By 1940, titles emerged which tended toward analyses of components of cellular pathology ("Comparison Between Polymorphonclear Leukocytes and Monocytes in Regard to Their Chemotactic Behavior," "Mechanisms of Leukocytosis with Inflammation: The Nature of the Leukocytosis-Promoting Factor"), along with extensive modeling of transformation and analysis of linked cellular events ("Studies in Carcinogenesis XI: Development of Skin Tumors in Mice Painted with 3:4-Benzpyrene and Creosote Oil Fractions").

The Journal has thus logically evolved to its current focus on the molecular pathobiology of human disease. Within the last year alone, marked content changes have been noted with increasing numbers of publications using novel approaches such as array- based genomic analyses. The first true proteomics papers have also been published within the last twelve months. It is particularly noteworthy that in this (arguably) centennial year, the first drafts of the human genome were reported, and the first genomics and proteomics papers began to appear in our Journal. Without a doubt, papers describing the effects of polymorphisms on disease processes will soon be routinely handled. A particularly exciting development for our field stems from the fact that the increasing reliance on mouse (and fly and worm) biology places many of the advances in pathobiology of disease back into a three-dimensional in vivo context-a context in which understanding of the architecture of disease, a strength of our field becomes once again a major focal point. These changes promise to reinvigorate the critical "bridge" function of experimental pathology, connecting the basic and clinical sciences.

\section{The Recast Editorial Group Looks Forward to Serving Our Authors}

The major role of the editors is to ensure uniform high quality, through the peer review process, of manuscripts submitted by our authors. As such, our role is one of service to both readership and authors. Given the in- 
creased quality and quantity of submissions, elements such as priority rankings have become critical to the final decision and this, at times, can be frustrating to authors. Hopefully, however, all will recognize the value of continuously increasing the quality of the Journal.

Although our current group of editors is recast it is not entirely new. Continuity in the editorial review process will be greatly helped by a group of editors who also served before the most recent transition: Drs. Nelson Fausto, Steven Kunkel, Patricia D'Amore, Jonathan Fletcher, Philip Furmanski, Sem Phan, and William Stetler-Stevenson. Additionally, a group of superb new editors have joined our ranks: Drs. Kenneth Bernstein, Wing (John) Chan, Lora Hedrick Ellenson, David Louis, Massimo Pignatelli, and Setsuo Hirohashi. I am particularly pleased to have Dr. Charles Parkos as the new Senior Associate Editor whose wisdom and reliability are greatly valued.

The Journal has also become more international in flavor with approximately $40 \%$ of published manuscripts now coming from outside of the United States. Accordingly, for the first time we are fortunate to have Associate Editors located in both Europe and Asia (Drs. Pignatelli and Hirohashi). Recognizing the multidisciplinary nature of the content of many papers, we will increasingly publish commentaries to place manuscripts in a broader context. We are also fortunate that Dr. Fausto has agreed to take responsibility for a new section, "This Month in AJP," which, in shorter form, accomplishes a similar goal of placing into context a number of highlighted articles in each issue. Importantly, however, the editors recognize that while such enhancements increase the accessibility of the content to the readership, the bread and butter of our task is still to ensure the uniformity of quality of the primary manuscripts published. We are fortunate to have a first class editorial office in Bethesda, under the guidance of Managing Editor Priscilla Markwood, to control the logistics of this process.

If one takes the originally assumed 1901 as the founding date of the Journal, our centennial year is thus marked by a recast editorial group with a renewed commitment to further serve our readership and authors and to continue the process of continuous incremental quality enhancement carried out so well by the previous group. It is also marked by a vigorous internationalism, an eye toward increasing accessibility of content to the readership but, most of all, a surrounding revolution in biology with great promise for improved understanding of human disease and enhanced positioning of our field in this process. We are indeed grateful for these opportunities.

James L. Madara

Editor-in-Chief 